\title{
Assessment of Modified-modified Schober Test and Lomber Range of Motion in Patients with Parkinson's Disease with and Without Low Back Pain
}

\author{
Bel A ğrısı Olan ve Olmayan Parkinson Hastalarında Modifiye Schober Test ve Lomber \\ Hareket Açıklı̆̆ının Dĕgerlendirilmesi
}

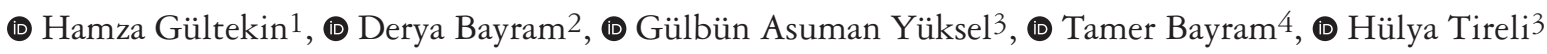

${ }^{1}$ Sirnak State Hospital, Intensive Care Unit, Sirnak, Turkey

2University of Health Sciences Turkey, Fatih Sultan Mehmet Training and Research Hospital, Clinic of Neurology, Istanbul, Turkey

3University of Health Sciences Turkey, Haydarpasa Numune Training and Research Hospital, Clinic of Neurology, Istanbul, Turkey

${ }^{4}$ University of Health Sciences Turkey, Fatih Sultan Mehmet Training and Research Hospital, Intensive Care Unit, Istanbul, Turkey

\begin{abstract}
Objective: We aimed to evaluate the relationship between low back pain (LBP) in patients with Parkinson's disease (PD) and its effects on the activities of daily living of the patients. We also observed the correlation between LBP and spinal mobility tests.

Materials and Methods: The study included 55 patients with PD, 39 males and 16 females, in Hoenh Yahr stage I-IV with an average age of $63 \pm 5$ (range, 38 82). We included age- and sex- matched 20 healthy controls who had no orthopedic disease, with a mean age of $65 \pm 7$ (range, 35-87). All participants had lomber magnetic resonance imaging to exclude disc or other degenerative pathologies. The modified-modified schober test (MMST), lumbar flexion and extension range of motion (ROM) measurement were applied for assessment of spinal mobility. Lomber flexion and extension ROM was assessed by using a universal goniometry. In addition, Roland Morris disability questionnaire (RMDQ), the Oswestry disability index (ODI), visual analogue scale for pain (VAS), the unified Parkinson's disease rating scale (UPDRS), activities of daily living scale (ADLs), fatigue severity scale and Beck's depression inventory were applied to patients. Spinal mobility and test results of patients and controls were compared.

Results: We found that the values of MMST, and flexion and extension ROM were significantly decreased in the patient group compared to controls ( $\mathrm{p}<0.05$ ). The Hoehn Yahr stage, UPDRS, RMDQ, ODI and VAS values were higher and MMST results were lower in patients with LBP than patients without LBP. In the multivariate analysis, the presence of LBP did not correlate with any of the parameters including age, sex, duration of disease, dominant symptom, ADL, depression, and fatigue severity.

Conclusion: The current study showed that as the clinical disability worsened, the complaints of LBP increased and spinal mobility test results decreased. Questioning and adequately treating pain could permit a better quality of life to patients with PD.

Keywords: Low back pain, Parkinson's disease, range of motion, modified schober test

Öz

Amaç: Parkinson hastalığında (PH) bel ağrısını ve hastaların günlük yaşam aktiviteleri üzerindeki etkilerini değerlendirmeyi amaçladık. Bel ağrısı ile spinal mobilite testleri arasındaki ilişkiyi de gözlemledik.

Gereç ve Yöntem: Çalışmaya, yaş ortalaması $63 \pm 5$ yıl (38-82 yaş aralı̆̆ında) olan 39 erkek ve 16 kadından oluşan, Hoehn Yahr evre I-IV, 55 idiopatik PH

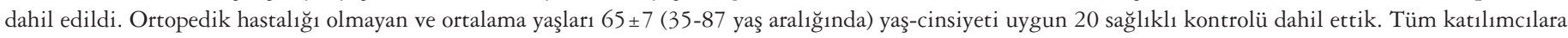
disk veya diğer dejeneratif patolojileri dışlamak için lomber manyetik rezonans görüntüleme uygulandı. Spinal mobilite değerlendirmesi için modifiye-modifiye schober testi (MMST), lomber fleksiyon ve ekstansiyon hareket açıklığı (ROM) ölçümü uygulandı. Lomber fleksiyon ve ekstansiyon ROM universal bir gonyometri ile değerlendirildi. Ayrıca hastalara Roland Morris dizabilite anketi (RMDQ), Oswestry dizabilite indeksi (ODI), ağrı için vizüel analog skalası (VAS), birleşik Parkinson hastalığg derecelendirme ölçeği (UPDRS), günlük yaşam aktiviteleri ölçeği, yorgunluk şiddeti ölçeği ve Beck’s depresyon envanteri uygulandı. Hasta ve kontrol gruplarının spinal mobilite ve test sonuçları karşılaştırıldı.
\end{abstract}

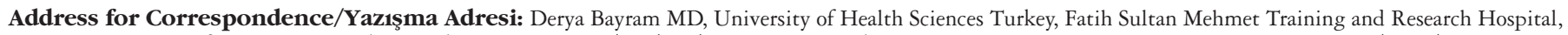
Clinic of Neurology, Istanbul, Turkey Phone: +90 5433400430 E-mail: deryak_30@hotmail.com ORCID: orcid.org/0000-0001-8184-5184

Received/Geliş Tarihi: 06.09.2020 Accepted/Kabul Tarihi: 07.02.2022

${ }^{\circ}$ Copyright 2022 by Turkish Neurological Society

Turkish Journal of Neurology published by Galenos Publishing House. 
Bulgular: PH grubunda MMST skoru, fleksiyon ve ekstansiyon ROM değerlerinin kontrol grubuna göre anlamlı olarak azaldı $\breve{g} ı$ ı bulduk (p<0,05). Bel ağrılı hastalarda bel ağrısı olmayanlara göre Hoenh Yahr evresi, UPDRS, RMDQ, ODI ve VAS değerleri daha yüksek, MMST sonuçları daha düşüktü. Çok değişkenli analizde bel ağrısının varlığı, yaş, cinsiyet, hastalık süresi, dominant semptom, günlük yaşam aktiviteleri, depresyon ve yorgunluk şiddeti dahil olmak üzere incelenen parametrelerin hiçbiriyle korele değildi.

Sonuç: Bu çalışma, klinik dizabilite kötüleştikçe bel ağrısı şikayetlerinin arttı̆̆ını ve spinal mobilite test sonuçlarının azaldı̆̆ı̆ı göstermiştir. Ağrıyı sorgulamak ve yeterince tedavi etmek, PH'ye daha iyi bir yaşam kalitesi să̆layabilir.

Anahtar Kelimeler: Bel ağrısı, Parkinson hastalığı, hareket açıklığ1, modifiye schober testi

\section{Introduction}

Idiopathic Parkinson's disease (PD) is defined as a neurodegenerative disease characterized by tremor, rigidity, bradykinesia and postural instability with the progressive loss of dopaminergic neurons in the pars compact section of the substantia nigra (1). In the course of PD besides the symptoms of movement disorder; sleep, neuropsychiatric, gastrointestinal and autonomic disorders, and sensory symptoms including pain could also be seen. Pain is not usually mentioned but is a typical non-motor symptom in PD and can occur before the occurrence of motor symptoms and makes diagnosis difficult. Traditionally, pain in PD is classified into five domains: Musculoskeletal pain (MSP), radicular/neuropathic pain, dystonia-related pain, akathitic pain and central pain (2). Primary central pain in PD has been attributed to a dysfunction of basal ganglia-thalamocortical circuits and sensory circuits within the basal ganglia (3). These mechanisms may also play a role in processing and augmentation of secondary pain arising from peripheral structures. Central pain is described as a faint tension or discomfort sensation that tends to improve with movement.

Low back pain (LBP) and decrease in spinal mobility are important in the follow-up of patients with PD from the beginning of disease and require a multidisciplinary approach. In the current study, we aimed to investigate the correlation between LBP and decrease in spinal mobility in patients with PD and the effects of pain on activities of daily living.

\section{Materials and Methods}

This was a retrospective study of patients treated between May 2000 and October 2015. All patients $(n=55)$ with a diagnosis of PD who were aged 38 to 82 years and were followed by the University of Health Sciences Turkey, Haydarpaşa Numune Training and Research Hospital Movement Disorders Outpatient Clinic participated in the study. The inclusion criteria were as follows: Having stages I- IV disease due to the Hoehn and Yahr (HY) scale (4), having neither disc nor other degenerative pathology on lumbar magnetic resonance imaging (MRI), having no diseases that affected the low back and lower limbs, and being stable on antiparkinson treatment. Patients with the diagnosis of disease other than PD, with severe mechanical LBP, and with history of spinal surgery were excluded. LBP was questioned in patients. The differential diagnosis between secondary pain to PD and osteoarthritis was made by both clinical history and physical examination. A control group consisting of 20 healthy patients, aged between 35-87 years without a history of orthopedic surgery, was included in the study. Control group also underwent lumbar MRI to exclude disc or other degenerative pathologies.

The degree of clinical disability of PD was assessed by using the Unified Parkinson's Disease Rating Scale (UPDRS) (5). The
UPDRS scores were obtained in the "on" state of the disease. The modified HY staging scale was used to determine the stage of PD. Roland Morris disability questionnaire (RMDQ) and the Oswestry disability index (ODI) were used to determine the functional status and disability of patients $(6,7)$. RMDQ assess how LBP affects the daily activities. Its cut-off point for patients with and without disability is 14 (6). The ODI is the questionnaire that questions patients' ability to manage everyday life and covers intensity of pain. Pain severity was assessed by using visual analogue scale (VAS) for pain (8). The modified-modified schober test (MMST) (9) and lumbar flexion and extension range of motion (ROM) measurements were applied for the assessment of spinal mobility. Firstly, results of patients with PD were compared with controls and in the second stage, results of patients with LBP and without LBP were compared with each other. Lomber ROM was assessed by using a universal goniometry. Measurements were made by the same neurologist to avoid differences. The measurement of lomber ROM was performed according to method described by Norkin and White (10). In the MMST, especially $4 \mathrm{~cm}$ and below shows that spinal mobility is significantly reduced.

In addition, activities of daily living scale (ADLs) (11), fatigue severity scale (FSS) (12), and Beck's depression inventory (BDI) (13) were applied to patients. Results of patients with PD with and without LBP were compared with each other.

Informed consent was obtained from each subject in accordance with the Declaration of Helsinki. The study protocol was approved by the Ethics Committee of the University of Health Sciences Turkey, Haydarpasa Numune Training and Research Hospital (protocol number: HNEAH-KAEK 2015/50).

\section{Statistical Analysis}

All analyses were performed by using SPSS software (version 22). In this study, descriptive statistics [number (n), percentage $(\%)$, mean, standard deviation, median, minimum and maximum values] were used for the demographic and clinical characteristics. Descriptive analyses were presented using median and interquartile ranges for the non-normally distributed and ordinal variables. Chi-square test and Mann-Whitney $\mathrm{U}$ test were used compare the measurements ofpatients with PD and control group. Some results of patients with $\mathrm{PD}$ were analyzed by using KruskalWallis test. Correlation coefficients and statistical significance for the relationships between variables were calculated with the Spearman correlation analysis. The level of statistical significance was accepted as $\mathrm{p}<0.05$.

\section{Results}

Fifty-five patients with PD participated in this study (16 females, 39 males). Thirty-tree patients $(60 \%)$ complained of LBP. There were 18 patients $(33 \%)$ with LBP from the beginning of disease. 
Bradykinesia was dominant in 35 patients $(63.6 \%)$ and tremor was dominant in 20 patients $(36.4 \%)$. The demographic and clinical features of the patients with PD were described in Table 1. Lumbar MRI of all patients and controls were within normal limits.

The control group was consisting of 20 healthy patients $(6$ females, 14 males), aged between 35-87 years. The mean age of 20 controls was $65 \pm 7$ years (between $35-87$ years). We made the first comparison between the patient and control group. In the control group, mean MMST score was $7 \pm 1 \mathrm{~cm}$. In $65.5 \%$ of the patients with PD, the mean MSST score was $\leq 4 \mathrm{~cm}$. The mean flexion ROM and extension ROM values of the control group were $47 \pm 7 \mathrm{~cm}$ and $37 \pm 6 \mathrm{~cm}$, respectively. The comparison of MMST scores of patients and controls was shown in Table 2. Mean values of flexion ROM was $36 \pm 19 \mathrm{~cm}$, extension ROM was $20 \pm 8 \mathrm{~cm}$

\begin{tabular}{ll} 
Table 1. Clinical features of the patients with Parkinson's \\
disease \\
Patients with Parkinson's disease & Mean value \\
\hline Duration of disease (years) & $5.55 \pm 3.90$ \\
\hline Age (years) & $63 \pm 5$ \\
\hline Age at onset (years) & $59 \pm 11$ \\
\hline UPDRS total & $32 \pm 19$ \\
\hline MMST (cm) & $4 \pm 1$ \\
RMDQ & $10 \pm 9$ \\
\hline Hoenh Yahr & $(\mathrm{I}-\mathrm{IV})$ \\
\hline Stage 1 & $3(5.45 \%)$ \\
\hline Stage 1.5 & $3(5.45 \%)$ \\
\hline Stage 2 & $14(25.5 \%)$ \\
\hline Stage 2.5 & $19(34.5 \%)$ \\
\hline Stage 3 & $11(20 \%)$ \\
\hline Stage 4 & $5(9.1 \%)$ \\
Flexion ROM & $36 \pm 19$ \\
Extension ROM & $20 \pm 8$ \\
ODI & $27 \pm 22$ \\
\hline VAS & $4 \pm 2$ \\
\hline FSS & $34 \pm 11$ \\
\hline ADLs & $7 \pm 3$ \\
\hline BDI & $15 \pm 6$ \\
\hline
\end{tabular}

UPDRS: Unified Parkinson's disease rating scale, RMDQ: Roland Morris disability questionnaire, ODI: Oswestry disability index, VAS: Visual analogue scale, MMST: The modified-modified schober test, ROM: Range of motion, ADLs: Activities of daily living scale, FSS: Fatigue severity scale, BDI: Beck's depression inventory

Table 2. Modified-modified schober test scores of patients and controls

\begin{tabular}{lllllll} 
& & \multicolumn{2}{l}{$\begin{array}{l}\text { Patients } \\
\text { group }\end{array}$} & \multicolumn{2}{l}{$\begin{array}{l}\text { Controls } \\
\text { group }\end{array}$} & p \\
MMST score & & n & $\%$ & n & $\%$ & \\
& $\leq 4 \mathrm{~cm}$ & 36 & $65.5 \%$ & 0 & $0 \%$ & \\
& $>4 \mathrm{~cm}$ & 19 & $34.5 \%$ & 20 & $100 \%$ & 0.015 \\
& &
\end{tabular}

Chi-square test was used, MMST: The modified-modified schober test in patients with PD. Comparative analysis of flexion ROM and extension ROM values between the patients and controls showed that flexion and extension ROM values were significantly lower in the PD group $(\mathrm{p}<0.05)$.

Fifty percent of females and $64 \%$ of males in the PD group, a total of 33 patients $(60 \%)$ suffered from LBP. Detailed data of the patients with and without LBP were shown in Table 3, 4. It was determined that $75 \%$ (12) of the females and $62 \%$ (24) of the males, who had reduced spinal mobility (MMST value $\leq 4 \mathrm{~cm}$ ), had higher HY stages, UPDRS, ODI and RMDQ values and lower flexion ROM values than patients without LBP $(p<0.05)$. In the multivariate analysis, the presence of LBP did not correlate with any of the parameters including age, sex, duration of disease, and clinical type of dominant symptom, ADL, depression, and fatigue severity in PD. There was no significant correlation between MMST and gender, clinical condition of disease, duration of disease, BDI, FSS, VAS and extension ROM. MMST values worsened with increasing age. The ADLs values were significantly lower in patients with reduced spinal mobility. Patients' characteristics according to the MMST were shown in Table 5.

Higher VAS and RMDQ values and higher UPDRS scores were with higher ODI levels as shown in Figure 1, 2, 3.

The UPDRS, BDI and FSS values were higher in bradykinesia dominant patients than in tremor dominant group $(\mathrm{p}<0.05)$. There were no significant differences in terms of spinal mobility values (MMST, ODI results), gender, age, and pain between two group ( $>>0.05)$.

\section{Discussion}

Neurophysiology of pain in patients with PD is not well understood. The abnormal function of basal nuclei directly modulates pain by increasing or decreasing nociceptive signal propagation (14). Pain in PD appears to involve serotonergic, noradrenergic, glutaminergic and GABA-ergic neurotransmission, in addition to the dopaminergic systems (15). Patients with PD are more troubled by chronic LBP than people with the same age (16). In addition, Zambito Marsala et al. (17) observed that pain tolerance threshold was lower in patients with PD as compared to healthy individuals by using electric stimulation. It was reported that the pain was significantly more frequently $(87.3 \%)$ located in the lumbar region in patients with $\mathrm{PD}$ with longer duration and that they had higher pain intensity (18). The prevalence of pain in $\mathrm{PD}$ ranges from $40 \%$ to $87.6 \%$ with the most common pain type appearing to be MSP $(2,3,18)$. In accordance with the literature we found the prevalence of LBP in PD to be $60 \%$. Changes in prevalence values may be due to inclusion criteria, age and disease severity of patients, localization and definition of pain, and involvement of patients from different centers. The patient group may consist of patients with relatively better functionality and earlier stages in studies with relatively low pain prevalence. In the study of Silveira Barezani et al. (19), $58.3 \%$ of patients had chronic LBP, and approximately $40 \%$ of patients reported its onset before diagnosis of PD. Similarly, in our study, $33 \%$ of the patients had pain at the time of diagnosis. However, in the study of Gonçalves et al. (20), there was no difference in terms of pain intensity when comparing individuals who had LBP before PD and who had LBP after PD. There was no correlation between pain intensity and age, 
Table 3. Demographic and clinical features of the patients with Parkinson's disease with and without low back pain

\begin{tabular}{|c|c|c|c|c|c|c|c|}
\hline & \multicolumn{7}{|l|}{ Pain } \\
\hline & \multicolumn{3}{|l|}{ Absent } & \multicolumn{3}{|l|}{ Present } & \multirow{2}{*}{$\mathrm{p}$} \\
\hline & Median & Per. 25 & Per. 75 & Median & Per. 25 & Per. 75 & \\
\hline UPDRS & 28 & 23 & 34 & 40 & 28 & 52 & 0.038 \\
\hline Hoehn Yahr (stage) & 2 & 1.5 & 3 & 2.5 & 2 & 4 & 0.045 \\
\hline Duration of disease (years) & 4 & 3 & 6 & 5 & 4 & 7 & 0.363 \\
\hline ADLs & 6 & 4 & 7 & 7 & 4 & 9 & 0.120 \\
\hline FSS & 33 & 26 & 36 & 35 & 24 & 41 & 0.667 \\
\hline RMDQ & 1 & 0 & 6 & 17 & 9 & 20 & 0.025 \\
\hline VAS & 2 & 1 & 3 & 5 & 4 & 6 & 0.036 \\
\hline
\end{tabular}

"Mann-Whitney U test was used, Per: Percentile, UPDRS: Unified Parkinson's disease rating scale, RMDQ: Roland Morris disability questionnaire, FLEX: Flexion, EXT: Extension, VAS: Visual analogue scale, ROM: Range of motion, ADLs: Activities of daily living scale, FSS: Fatigue severity scale, BDI: Beck's depression inventory

Table 4. Clinical features of the patients with Parkinson's disease with and without low back pain

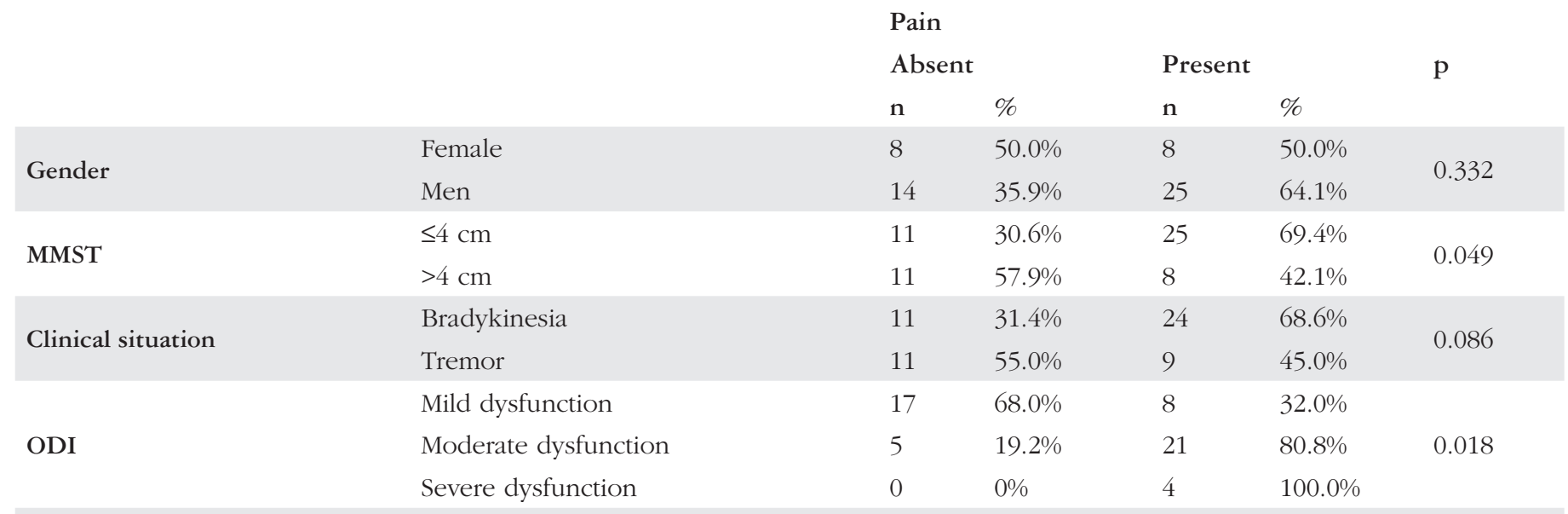

${ }^{*}$ Chi-square test was used. MMST: The modified-modified schober test, ODI: Oswestry disability index

time of symptoms and time of PD diagnosis.

Ford classified pain directly or indirectly associated with PD and its treatment in five different classes: a) MSP, b) radicularneuropathic pain, c) dystonic pain, d) central pain, e) druginduced or "off-period" akathisia (2). Patients may suffer from more than one pain subtype. Off-periods could worsen sensations such as neuropathic or visceral pain. Central pain is experienced as dysesthesias such as burning, tingling, pruritus or painful symptoms of a visceral/autonomic quality (21). Serratrice and Michel (22), unlike Ford, divided pain in PD into two main groups in their classification as PD-related or PD-unrelated pain. The current study aimed to correlate directly or indirectly PD-related pain with spinal mobility measurements and daily life activities. Although MMST scores, and flexion and extension ROM values of patients with PD were lower than controls $(\mathrm{p}<0.05)$, flexion and extension ROM values didn't differ between patients with PD with and without pain. This result suggested that severity of PD and natural course of the disease affected the reduction of spinal mobility as a separate factor from pain. In addition, we found the spinal mobility of the patients with PD with LBP decreased compared to PD patients without LBP and clinical disability scores of these patients were worse $(\mathrm{p}<0.05$ for ODI, MMST and RMDQ). Higher values in UPDRS and more advanced stages of $\mathrm{PD}$ were associated with poor functional limitation induced by LBP. There were no differences in terms of duration of disease and ADLs values between patiens with PD with and without LBP. In this study, patients with PD with LBP had higher VAS scores than patients with PD without LBP as expected. These patients with higher VAS scores had higher ODI scores, but their MSST score was not statistically different. Lower spinal mobility score didn't correlate with higher VAS score. Ozturk and Kocer (23) and Khlebtovsky et al. (24) have already reported associations between pain intensity and functional disability in individuals with PD. In study of Silveira Barezani et al. (19), patients with LBP had higher 


\begin{tabular}{|c|c|c|c|c|c|c|c|}
\hline & Modifiec & dified s & ber test & & & & \\
\hline & $\leq 4 \mathrm{~cm}$ & & & $>4 \mathrm{~cm}$ & & & \\
\hline & Median & Per. 25 & Per. 75 & Median & Per. 25 & Per. 75 & $\mathrm{P}$ \\
\hline Age (years) & 75 & 66 & 80 & 67 & 60 & 75 & 0.022 \\
\hline UPDRS & 39 & 28 & 53 & 25 & 19 & 34 & 0.004 \\
\hline HY (stage) & 3 & 2.5 & 4 & 2 & 1 & 2.5 & 0.025 \\
\hline Duration of disease (years) & 5 & 4 & 8 & 4 & 2 & 6 & 0.110 \\
\hline BDI & 13 & 8 & 17 & 11 & 4 & 15 & 0.169 \\
\hline ADLs & 5 & 3 & 7 & 7 & 5 & 10 & 0.019 \\
\hline FSS & 35 & 27 & 41 & 30 & 24 & 41 & 0.181 \\
\hline RMDQ & 13 & 4 & 20 & 1 & 0 & 16 & 0.007 \\
\hline VAS & 5 & 2 & 6 & 2 & 1 & 5 & 0.126 \\
\hline FLX ROM & 25 & 19 & 40 & 44 & 33 & 58 & 0.008 \\
\hline EXT ROM & 18 & 13 & 24 & 20 & 14 & 28 & 0.366 \\
\hline
\end{tabular}

*Mann-Whitney U test used. UPDRS: Unified Parkinson's disease rating scale, RMDQ: Roland Morris disability questionnaire, VAS: Visual analogue scale, ROM: Range of motion, ADLs: Activities of daily living scale, FSS: Fatigue severity scale, BDI: Beck's depression inventory, HY: Hoenh Yahr

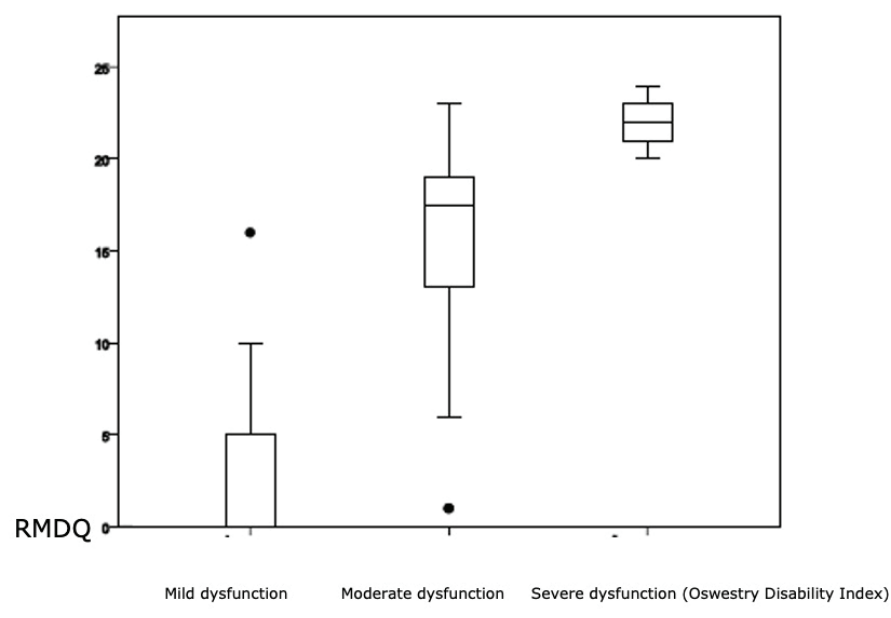

Figure 1. RMDQ and ODI

RMDQ: Roland Morris disability questionnaire, ODI: Oswestry disability index

scores in pain intensity, UPDRS, more advanced stages of PD, depressive symptoms and limited functionality. A recent study also suggested that an association existed between functional mobility and ROM of the trunk for the flexion, extension and rotation (both sides) movements. Moreover, these measurements in patients with PD were correlated with quality of life and functional mobility (25).

Patients with the hypokinetic PD subtype tend to experience more pain intensity (26). We reported that $68.6 \%$ of patients with bradykinesia dominant PD and $45 \%$ of patients with tremor dominant PD had pain in accordance with the literature. Moreover, we found no correlation between dominant symptom of the patients (bradykinesia or tremor) and pain.

Association between pain and depression in patients with PD is little known. Depression can be an important factor to trigger the pain. Starkstein et al. (27) have shown that pain is

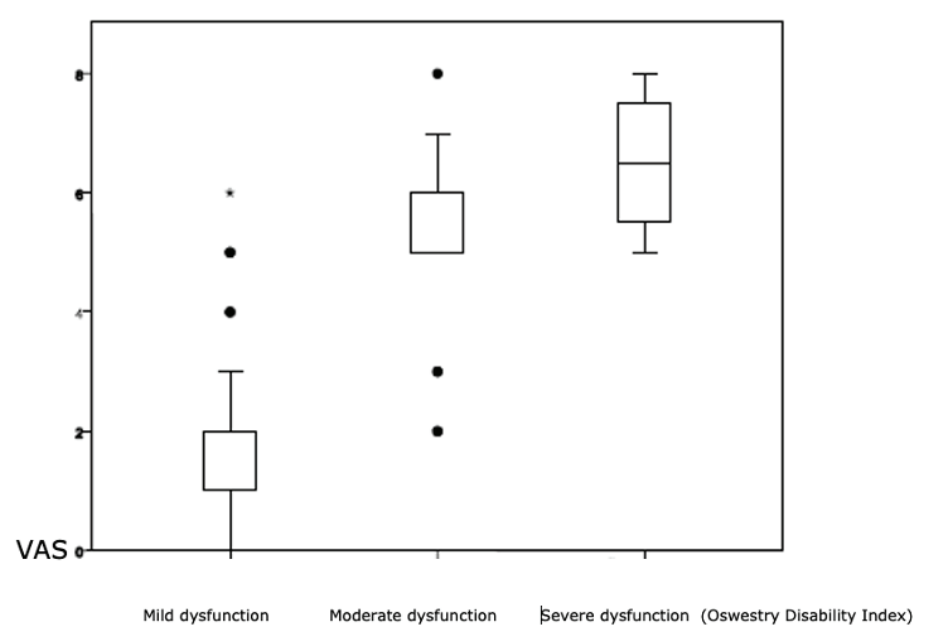

Figure 2. VAS and ODI

VAS: Visual analogue scale, ODI: Oswestry disability index

significantly more severe in patients with major depression than in patients with minor or no depression. Ehrt et al. (28) also found a significant relationship between pain and depression in patients with PD. Differently, Tinazzi et al. (29) and Letro et al. (3) suggested that depression was not associated with pain in PD, as in our study. Our results are consistent with some of studies in PD which have reported no relation between pain and depressive complaints $(\mathrm{p}=0.128)$. In addition, there was no patient with severe depression according to BDI in our study. Association between depression and pain might change due to disease stages and patients' levodopa responds.

Pain complaints might increase with advancing age and pain intensity could differ in genders. Lien et al. (30) showed that PD might significantly increase the risk of developing MSP especially for middle-aged male patients. Unlike Lien et al. (30), severity of fatigue and pain were more common and severe in women in 


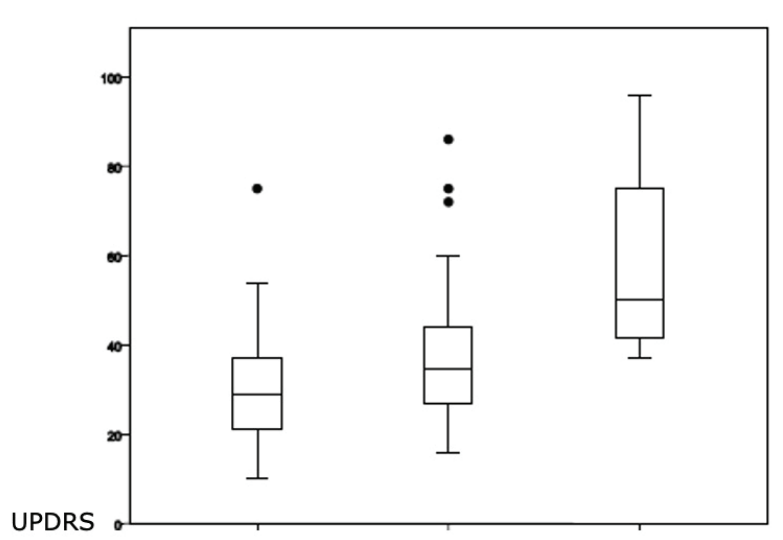

Mild dysfunction Moderate dysfunction Severe dysfunction (Oswestry Disability Index)

Figure 3. UPDRS and ODI

UPDRS: Unified Parkinson's disease rating scale, ODI: Oswestry disability inde

the study of Martinez-Martin et al. (31). In addition, Gonçalves et al. (20) reported higher intensity of pain in women among the individuals of patients with LBP (22). Our results indicated that there was no correlation between pain and age, gender, fatigue severity. Further studies will be needed to reach a definitive conclusion.

Previous studies have shown that L-dopa can reverse primary sensory pain related to parkinsonism (2). However, one of the common side effects of levodopa is muscle pain. All patients in our study were under levodopa or its combination therapy. Quinn et al. (32) found a complex relationship between pain and L-dopa and pointed out that pain occurred in low-dopa states in most patients but might also occasionally be exacerbated in high-dopa states, usually associated with dystonia or peak-dose dyskinesias. Gabapentin is well-tolerated in PD and may have a minor positive effect on motor symptoms (33). Pregabalin, lamotrigine or carbamazepine and tricyclic antidepressants also should be tried. Surgical methods have also been tried in the treatment of pain in PD. Since the natural course of PD is progressive, the outcome after lumbar surgery is poor due to the high rate of both acute and delayed complications (34). Another small invasive surgical method, spinal cord stimulation, is usually well tolerated and has also been shown to have positive effects on parkinsonian symptoms (18).

\section{Study Limitations}

This study was limited by low statistical power for patient sample size. Further studies with larger sample size would be needed. And we did not give detailed information about the character of the pain in patients with PD. The strength of the present study was that patients were investigated with validated instruments for PD, pain and disability, and our results were in line with previous studies.

\section{Conclusion}

To our best knowledge, this is the first study investigating the relationship between LBP and MMST, lomber flexion-extension ROM and other relevant constructs in PD as spinal mobility and quality of life. We observed that spinal mobility of patients with
PD was significantly decreased compared to the control group and MMST values of patients with PD with LBP were lower than patients with PD without LBP. Natural course of the disease might affect the reduction of spinal mobility. We found no significant difference in age, duration of disease, dominant symptom, ADLs, BDI and FSS values of PD patients with and without LBP. Patients with higher UPDRS score and HY stages had limitation of spinal mobility. Generally, pain in patients with PD is often neglected or insufficiently treated. Patients can benefit from appropriate passive ROM exercises and physical therapy. Therefore, we believe that pain is a non-motor symptom that needs to be further questioned in the follow-up of PD, to permit a better quality of life to patients.

Ethics

Ethics Committee Approval: The study protocol was approved by the Ethics Committee of the University of Health Sciences Turkey, Haydarpasa Numune Training and Research Hospital (protocol number: HNEAH-KAEK 2015/50).

Informed Consent: Informed consent was obtained from each subject.

Peer-review: Externally peer-reviewed.

\section{Authorship Contributions}

Concept: H.G., G.A.Y., D.B., H.T., Design: D.B., T.B., Data Collection or Processing: H.G., T.B., D.B., Analysis or Interpretation: G.A.Y., H.T., D.B., Literature Search: G.A.Y., H.T., D.B., Writing: D.B., H.G., T.B.

Conflict of Interest: No conflict of interest was declared by the authors.

Financial Disclosure: The authors declared that this study received no financial support.

\section{References}

1. Adler $\mathrm{CH}$, Ahlskog JE. Parkinson's disease and movement disorders diagnosis and treatment guidelines for the practicing physician. Totowa (NJ): Humana Press, 2000.

2. Ford B. Pain in Parkinson's disease. Mov Disord 2010;25(Suppl 1):98-103.

3. Letro GH, Quagliato EM, Viana MA. Pain in Parkinson's disease. Arq Neuropsiquiatr 2009;67:591-594.

4. Hoehn MM, Yahr MD. Parkinsonism: onset, progression and mortality. Neurology 1967;17:427-442.

5. Movement disorder society task force on rating scales for Parkinson's disease. The unified Parkinson's disease rating scale (UPDRS): status and recommendations. Mov Disord 2003;18:738-750.

6. Küçükdeveci AA, Tennant A, Elhan AH, Niyazoglu H. Validation of the Turkish version of the Roland-Morris Disability Questionnaire for use in low back pain. Spine (Phila Pa 1976) 2001;26:2738-2743.

7. Yakut E, Düger T, Oksüz C, Yörükan S, et al. Validation of the Turkish version of the oswestry disability index for patients with low back pain, spine. (Phila Pa 1976) 2004;29:581-585.

8. Price DD, McGrath PA, Rafii A, Buckingham B. The validation of visual analogue scales as ratio scale measures for chronic and experimental pain. Pain 1983;17:45-56.

9. Tousignant M, Poulin L, Marchand S, Viau A, Place C. The modifiedmodified schober test for range of motion assessment of lumbar flexion in patients with low back pain: a study of criterion validity, intra- and interrater reliability and minimum metrically detectable change. Disabil Rehabil 2005;27:553-559.

10. Norkin CC, White DJ. Measurement of joint motion: a guide to goniometry 5th ed.F.A. Davis Company: Philadelphia; 2016.

11. Hobson JP, Edwards NI, Meara RJ. The Parkinson's disease activities of daily living scale: a new simple and brief subjective measure of disability in Parkinson's disease. Clin Rehabil 2001;15:241-246. 
12. Herlofson K, Larsen JP. Measuring fatigue in patients with Parkinson's disease-the fatigue severity scale. Eur J Neurol 2002;9:595-600.

13. Beck AT, Steer RA, Brown G. Beck depression inventory-II. Psychological Assessment, 1996.

14. Truini A, Frontoni M, Cruccu G. Parkinson's disease related pain: a review of recent findings. J Neurol 2013;260:330-334.

15. Barone P. Neurotransmission in Parkinson's disease: beyond dopamine. Eur J Neurol 2010;17:364-376.

16. Kim YE, Lee WW, Yun JY, et al. Musculoskeletal problems in Parkinson's disease: neglected issues. Parkinsonism Relat Disord 2013;19:666-669.

17. Zambito Marsala S, Tinazzi M, Vitaliani R, et al. Spontaneous pain, pain threshold, and pain tolerance in Parkinson's disease. J Neurol 2011; 258:627-633.

18. Galazky I, Caspari C, Heinze HJ, Franke J. The prevalence of chronic low back pain and lumbar deformities in patients with Parkinson's disease: implications on spinal surgery. Eur Spine J 2018;27:2847-2853.

19. Silveira Barezani AL, de Figueiredo Feital AMB, Gonçalves BM, Christo PP, Scalzo PL. Low back pain in Parkinson's disease: A cross-sectional study of its prevalence, and implications on functional capacity and quality of life. Clin Neurol Neurosurg 2020;194:105787.

20. Gonçalves BM, Barezani ALS, de Figueiredo Feita AMB, de Souza MS, Christo PP, Scalzo PL. Low back pain prevalence in Parkinson's disease. BrJP. São Paulo 2020;3:310-313.

21. Sophie M, Ford B. Management of Pain in Parkinson's disease. CNS Drugs 2012;26:937-948.

22. Serratrice G, Michel B. Pain in Parkinson's disease patients. Rev Rhum Engl Ed 1999;66:331-338.

23. Ozturk EA, Kocer BG. Predictive risk factors for chronic low back pain in Parkinson's disease. Clin. Neurol Neurosurg 2018;164:190-195.
24. Khlebtovsky A, Djaldetti R, Rodity Y, et al. Progression of postural changes in Parkinson's disease: quantitative assessment. J Neurol 2017;264:675683.

25. Cano-de-la-Cuerda R, Vela-Desojo L, Moreno-Verdú M, et al. Trunk range of motion is related to axial rigidity. functional mobility and quality of life in Parkinson's disease: an exploratory study. Sensors (Basel) 2020;20:2482.

26. Tıraş Gürdal R, Özer F, Atmaca B, et al. Clinical properties of pain and prevalence of morbid and premorbid pain in idiopathic Parkinson's disease. Parkinson Hastalığı ve Hareket Bozuklukları Dergisi 2008;11:7-16.

27. Starkstein SE, Preziosi TJ, Robinson RG. Sleep disorders, pain, and depression in Parkinson's disease. Eur Neurol 1991;31:352-355.

28. Ehrt U, Larsen JP, Aarsland D. Pain and its relationship to depression in Parkinson disease. Am J Geriatr Psychiatry 2009;17:269-275.

29. Tinazzi M, Del Vesco C, Fincati E, et al. Pain and motor complications in Parkinson's disease. J Neurol Neurosurg Psychiatry 2006;77:822-825.

30. Lien WH, Lien WC, Kuan TS, et al. Parkinson disease and musculoskeletal pain: an 8-year population-based cohort study. Pain 2017;158:1234-1240.

31. Martinez-Martin P, Falup Pecurariu C, Odin P, et al. Gender-related differences in the burden of non-motor symptoms in Parkinson's disease. J Neurol 2012;259:1639-1647.

32. Quinn NP, Koller WC, Lang AE, Marsden CD. Painful Parkinson's disease. Lancet 1986;1:1366-1369.

33. Van Blercom N, Lasa A, Verger K, et al. Effects of gabapentin on the motor response to levodopa: a double-blind, placebo-controlled, crossover study in patients with complicated Parkinson disease. Clin Neuropharmacol 2004; $27: 124-128$.

34. Schroeder JE, Hughes A, Sama A, et al. Lumbar spine surgery in patients with Parkinson disease. J Bone Joint Surg Am 2015;97:1661-1666. 